\title{
Transformação pragmática da filosofia kantiana: Habermas, leitor de Humboldt
}

\author{
Antonio Ianni Segatto \\ Doutorando em Filosofia na Faculdade de Filosofia, \\ Letras e Ciências Humanas da Universidade de São \\ Paulo e bolsista da FAPESP.
}

\begin{abstract}
Resumo: $\mathrm{O}$ artigo examina a maneira como Habermas interpreta a filosofia da linguagem de Humboldt e a maneira como recupera e radicaliza a ideia de uma "transformação pragmática da filosofia kantiana" presente na obra deste autor.

Abstract: The article examines Habermas' interpretation of Humboldt's philosophy of language and the way he recovers and radicalizes the idea of a "pragmatic transformation of Kantian philosophy" in the work of Humboldt.

Palavras-chave:Habermas, Humboldt, virada lingüística, pragmática.

Keywords: Habermas, Humboldt, linguistic turn, pragmatics.
\end{abstract}

Em uma das inúmeras réplicas que dirige a seus críticos, Habermas propõe uma reformulação, que inicialmente parece não passar do nível da mera analogia, para a pergunta kantiana a respeito das condições de possibilidade do conhecimento. No mesmo trecho, ele encaminha uma resposta surpreendente, ao menos à primeira vista, pois aponta para o sentido oposto da analogia inicial:

Se, mantendo uma certa analogia com a crítica kantiana da razão, procuramos responder à pergunta sobre como é possível o uso da linguagem orientado para o entendimento, deparamo-nos com o saber intuitivo dos sujeitos capazes de falar e agir, que a criança deve aprender para poder, quando adulta, empregá-la na ação comunicativa. ${ }^{1}$

1. Habermas, J. "Replik auf Einwände". In: Vorstudien und Ergänzungen zur Theorie des kommunikativen Handelns. Frankfurt am Main: Suhrkamp, 1984, p. 497-8. 
A reformulação, como dissemos, parece não passar da mera analogia: nos Prolegômenos, por exemplo, Kant perguntava-se pelas condições do conhecimento teórico ("como é possível o conhecimento pela razão pura?"); Habermas, por seu turno, pergunta-se pelas "condições normativas do entendimento possível" ("como é possível o uso da linguagem orientado para o entendimento?" ou, conforme a formulação da Thomas McCarthy, "como é possível em geral o entendimento entre sujeitos capazes de falar e agir?"). No entanto, pouco a pouco, a simples troca de etiquetas vai se revelando uma transformação decisiva da filosofia kantiana. Embora se trate em ambos os casos do questionamento em relação a condições supostamente universais, estas são, no primeiro, as condições subjetivas da experiência objetiva e, no segundo, as condições intersubjetivas do entendimento por meio da linguagem. E essa transformação é ainda mais patente no que concerne ao tipo de investigação que a questão sobre as "condições normativas do entendimento possível” impõe. É certo que, como Kant, Habermas adota uma perspectiva universalista de investigação. No entanto, recusando qualquer tipo de dedução a priori, ele assinala que o saber pré-teórico dos sujeitos capazes de falar só pode ser abordado a partir de reconstruções racionais a posteriori. Thomas $\mathrm{McCarthy,}$ um de seus colaboradores mais próximos, resume esse ponto com as seguintes palavras:

Tais reconstruções podem ser comparadas em seu alcance e estatuto com teorias gerais (por exemplo, da linguagem e da cognição). De um outro ponto de vista, elas podem ser comparadas com a lógica transcendental de Kant. Mas as diferenças aqui são críticas. As reconstruções racionais das competências universais não podem reivindicar as pretensões fortes e a priori do projeto kantiano. Elas são desenvolvidas segundo uma atitude hipotética e precisam ser checadas e revisadas à luz dos dados, que são recolhidos a posteriori nas performances reais e avaliados pelos sujeitos competentes. ${ }^{2}$

2. McCarthy, T. Ideals and illusions: on reconstruction and deconstruction in contemporary Critical Theory. Cambridge, Mass.: MIT Press, 1993, p. 131. 
O elemento mais fundamental do saber pré-teórico a ser reconstruído é a intuição segundo a qual o entendimento é o telos da comunicação lingüística. Apontando novamente para uma analogia com a filosofia kantiana, Habermas compara-a ao "fato da razão". Se para Kant essa noção, em um dos seus sentidos, designava uma verdade imediatamente conhecida pela razão $o^{3}$, para Habermas ela designa uma verdade imediatamente certa e imediatamente conhecida pelos sujeitos no momento em que se põem em situação de diálogo. É apenas a partir da suposição de que a comunicação lingüística está orientada por um entendimento possível que um falante e seus interlocutores podem começar a dialogar. A intuição segundo a qual o entendimento é o telos da comunicação lingüística, tomada enquanto uma verdade imediatamente certa, figura como o grau zero da enunciação.

Essas transformações são motivadas pela recepção de uma certa linhagem filosófica: a virada lingüística. Não por acaso, Habermas atribui a formulação da intuição mencionada à leitura das duas versões complementares da virada lingüística: a linhagem analítica e a linhagem hermenêutica. Em uma entrevista, ele declara:

Devo a uma recepção tanto da versão hermenêutica quanto da versão analítica da teoria da linguagem - poder-se-ia dizer, a uma leitura de Humboldt iluminada pela filosofia analítica - aquela intuição que explicitei em minha Teoria da ação comunicativa. Esta é a intuição segundo a qual o telos do entendimento mútuo está instalado na comunicação lingüística. ${ }^{4}$

3. Cumpre notar que o "fato da razão" na filosofia kantiana pode ser entendido no sentido de um fato (Tatsache), isto é, de uma verdade imediatamente conhecida pela razão, ou no sentido de um feito, isto é, de um ato ou decisão da razão. Habermas estabelece a analogia apenas em relação ao primeiro sentido. Sobre os vários sentidos desse conceito em Kant, cf. Almeida, G. A. de. "Kant e o facto da razão". In: MacDowell, J. A. (org.). Saber filosófico, história e transcendência. São Paulo: Ed. Loyola, 2002.

4. Habermas, J. "Dialektik der Rationalisierung". In: __. Die Neue Unübersichtlichkeit. Kleine Politische Schriften V. Frankfurt am Main: Suhrkamp, 1985, p. 173. 
A fim de compreender as razões e algumas outras implicações dessas transformações, é preciso retomar, ainda que a traços largos, a leitura que Habermas faz de Hamann e, sobretudo, Humboldt. Situando-os numa linhagem que se inicia no final do século XVIII, eles teriam sido responsáveis por iniciar a dissolução da concepção tradicional de linguagem, que perpassa a filosofia da consciência, como mero "instrumento" para a designação de entidades extra-lingüísticas e para a exteriorização de pensamentos. Como escreve Cristina Lafont, cuja leitura Habermas subscreve quase integralmente:

Retrospectivamente, pode-se considerar dessa perspectiva a crítica de Hamann a Kant como o núcleo de uma tal mudança de paradigma. Foi Hamann quem localizou na linguagem a raiz comum da sensibilidade e do entendimento buscada por Kant, elevando-a, com isso, a um estatuto não apenas empírico, mas ao mesmo tempo transcendental. É precisamente esse passo que converte a linguagem em uma instância que concorre com o 'eu transcendental' (ou a 'consciência em geral'), na medida em que pode reivindicar para si a autoria dos rendimentos constitutivos da experiência (ou do 'mundo') falsamente atribuídos àquele. ${ }^{5}$

De modo geral, podemos dizer que são dois os traços fundamentais dessa virada lingüística: em primeiro lugar, como conseqüência da superação da concepção tradicional da linguagem como "instrumento", ela é considerada como elemento constitutivo do pensamento e do conhecimento e, nessa medida, é considerada como condição de possibilidade tanto da objetividade da experiência quanto da intersubjetividade da comunicação; em segundo lugar, a superação das premissas da filosofia da consciência, conduz a uma necessária destranscendentalização da razão: a linguagem manifesta-se sempre em línguas particulares e históricas e não permite, por isso, uma separação estrita entre o transcendental e o empírico, entre o a priori e o a posteriori.

5. Lafont, C. “Apertura del mundo' y referencia”. In: Vieja, M. T. L. de la (ed.). Figuras del logos: entre la filosofía y la literatura. México D. F.: Fondo de Cultura Económica, 1994, p. 272. 
Ambos os traços podem ser encontrados no leitmotiv de Hamann segundo o qual a "razão é linguagem, logos" (ou, ainda, "sem a palavra, não há razão - nem mundo") e em sua fórmula segundo a qual a linguagem é "a priori arbitrária e contingente, mas a posteriori necessária e indispensável”. ${ }^{6}$ Com o primeiro, ele expressa sua metacrítica ao purismo da razão kantiana:

essa metareflexão é levada a cabo por Hamann por meio de uma questão que Kant não respondeu, na medida em que ele se 'esqueceu' de colocar: 'como é possível a faculdade de pensar?'. Apenas pela recordação de tal questão Kant poderia ter descoberto que 'a faculdade de pensar está na linguagem".

Com a segunda, ele ressalta, por um lado, que a linguagem, por ser "a priori arbitrária e contingente", não pode ser deduzida de nada anterior e depende, para se manifestar, de suas realizações concretas na história (as línguas particulares); e, por outro lado, que ela é "a posteriori necessária e indispensável", na medida em que possui um caráter constitutivo para aqueles que a utilizam.

Esse passo é decisivo para Habermas na formulação de algumas noções de sua teoria, como podemos notar na seguinte passagem:

Já Hamann levantara contra Kant a censura do 'purismo da razão'. Não há uma razão que só posteriormente vestiria roupagens lingüísticas. A razão é originalmente uma razão encarnada tanto nos contextos de ações comunicativas como nas estruturas do mundo da vida. ${ }^{8}$

Em outras palavras, a metacrítica de Hamann a Kant abre a possibilidade de pensar uma razão que não esteja circunscrita aos

6. Hamann, J. G. "Metacrítica sobre o purismo da razão". In: Gil, F. (org.). Recepção da Crítica da razão pura: antologia de escritos sobre Kant (17861844). Lisboa: Fundação Calouste Gulbenkian, 1992, p. 146.

7. Lafont, C. The linguistic turn in hermeneutic philosophy. Cambridge, Mass.: MIT Press, 1999, p. 8.

8. Habermas, J. Der philosophische Diskurs der Moderne. Frankfurt am Main: Suhrkamp, 1985, p. 374 (trad.: Habermas, J. O discurso filosófico da modernidade. São Paulo: Martins Fontes, 2000, p. 447). 
limites da consciência e do sujeito singular; uma razão que esteja, antes, situada nas próprias práticas comunicativas cotidianas.

Ocorre que ao situar a razão na linguagem, a concepção de Hamann conduz a um certo relativismo lingüístico tanto no que diz respeito à objetividade da experiência quanto no que diz respeito à intersubjetividade da comunicação. Mais uma vez recorrendo à formulação de Cristina Lafont:

essa peculiar mudança de paradigma leva, no que se refere à objetividade da experiência (isto é, no eixo linguagem-mundo), à dissolução da unidade transcendental da apercepção em uma diversidade de perspectivas ou aberturas do mundo inerentes às línguas históricas e, por isso, tão contingentes e historicamente cambiantes como estas (...) Em segundo lugar, esse tipo de virada lingüística traz consigo, no que se refere à intersubjetividade da comunicação (isto é, no eixo linguagem-linguagem) e devido igualmente à incomensurabilidade das perspectivas de mundo inerentes às diferentes línguas, a dúvida em relação à possibilidade de alcançar um entendimento sobre o mesmo a partir de diferentes línguas. ${ }^{9}$

Humboldt, por seu turno, parece dar continuidade a essa espécie de relativismo lingüístico. Cumpre lembrar que uma das teses centrais de suas reflexões é a de que "em cada língua encontra-se uma perspectiva de mundo (Weltansicht) particular". ${ }^{10}$ No entanto, cumpre lembrar também que essa tese deve-se menos a uma adesão explícita de Humboldt ao relativismo e mais aos pressupostos centrais de sua concepção de linguagem. Ao considerar as línguas em sua função de abertura do mundo, Humboldt converte-as em uma instância constitutiva de nossa perspectiva sobre ele; mas, sendo tais línguas plurais e historicamente modificáveis, as perspectivas do mundo subjacentes a elas também o serão.

Atento a isso, Habermas recorda que Humboldt examina a linguagem sob dois pontos de vista distintos, correspondentes

9. Lafont, C.; Peña, L. "La tradición humboldtiana y el relativismo lingüístico". In: Dascal, M. (Ed.). Filosofia del languaje II. Pragmática. Madrid: Editorial Trotta, 1999, p. 193.

10. Humboldt, W. von. Schriften zur Sprachphilosophie (Werke III). Darmstadt: Wissenchaftliche Buchgesellchaft, 2002, p. 224. 
às combinações de suas três funções principais, a saber: a função cognitiva, que permite formar pensamentos e representar fatos; a função expressiva, que permite exprimir sentimentos e suscitar sensações; e a função comunicativa, que permite comunicar algo, replicar e produzir acordos. De um ponto de vista semântico, assume proeminência o papel de organização de conteúdos lingǘsticos compartilhados por uma determinada comunidade; de um ponto de vista pragmático, assume proeminência o papel de médium do entendimento mútuo entre interlocutores. Segundo Habermas:

enquanto a análise semântica se concentra na visão de mundo lingüistica, para a análise pragmática a conversação está em primeiro plano. Enquanto lá Humboldt trata a função cognitiva da linguagem em conexão com os traços expressivos da mentalidade e da forma de vida de um povo, ele aqui tematiza a mesma função na conexão com discursos em que os participantes podem oferecer respostas e contradizer. ${ }^{11}$

A conjunção de ambos os pontos de vista sobre a linguagem instaura no empreendimento de Humboldt uma tensão entre o particularismo da abertura lingüística do mundo (ligado ao ponto de vista semântico) e o universalismo de uma prática voltada para o entendimento mútuo (ligado ao ponto de vista pragmático). Segundo Habermas, filósofos como Heidegger, Gadamer e Taylor tendem a dissolver essa tensão, ocupando-se apenas com um de seus pólos. Coloca-se, pois, o desafio de mostrar como tal tensão pode se estabilizar em uma concepção de linguagem como órgão formador do pensamento e, ao mesmo tempo, como médium do entendimento mútuo.

Além disso, Habermas procura ressaltar, em sua leitura de Humboldt, um outro aspecto também decisivo na concepção do

11. Habermas, J. "Hermeneutische und analytische Philosophie. Zwei komplämentare Speilarten der linguistischen Wende". In: . Wabrheit und Rechtfertigung. Frankfurt am Main: Suhrkamp, 1999, p. 67 (trad.: Habermas, J. "Filosofia hermenêutica e filosofia analítica: duas versões complementares da virada lingüística”. In: Verdade e Justificação. São Paulo: Edições Loyola, 2004, p. 65). 
autor. Trata-se da compreensão da linguagem não como um sistema acabado, mas como atividade. Nas palavras de Humboldt: "é preciso considerar a linguagem não como um produto morto (todtes Erzeugtes), mas, sobretudo, como uma produção (Erzeugung) (...) Em si mesma, a linguagem não é um produto (Ergon), mas uma atividade (Energeia)". ${ }^{12}$ Esses dois aspectos da linguagem, lembra Habermas, foram retomados tanto pelos teóricos quanto pelos filósofos da linguagem. No entanto, isso não se deu sem algum prejuízo. Por um lado, Saussure e Chomsky retomam o par ergon/energeia com as distinções língua/fala e competência lingüística/performance lingüística. Apesar disso, ambos desconsideram a função da linguagem como mediação do entendimento: "nem Saussure nem Chomsky compreendem como Humboldt a conversação como centro da linguagem". ${ }^{13}$ Por outro lado, filóso-

12. Humboldt, W. von. Schriften zur Sprachphilosophie (Werke III), p. 416 e 418.

13. Habermas, J. "Entgegnung". In: Honneth, A.; Joas, H. (Hgg.). Kommunikatives Handeln. Beiträge zu Jürgen Habermas' "Theorie des kommunikativen Handelns". Frankfurt am Main: Suhrkamp, 1986, p. 328. Embora Chomsky procure elaborar uma gramática gerativa, ele pode reconstruir apenas as regras fixas que permitem a geração de enunciados, mas não as regras que operam na produção real da fala e na situação de diálogo, as quais permanecem totalmente indeterminadas. Isso fica patente na leitura que faz de Humboldt: "O relevo dado por Descartes ao aspecto criador do uso da linguagem, como característica essencial e definidora da linguagem humana, encontra sua mais eficaz expressão na tentativa, feita por Humboldt, de criar uma ampla teoria da lingüística geral. A caracterização da linguagem, dada por Humboldt, como energeia (Thätigkeit [atividade]) mais do que como ergon (Werk [ato]), como 'eine Erzeugung' (uma produção) mais do que 'ein todtes Erzeugtes' (um produto morto) estende e remodela - muitas vezes quase com as mesmas palavras - as formulações típicas da lingüística cartesiana e da filosofia romântica da linguagem e da teoria estética. Para Humboldt, a única definição verdadeira da linguagem é 'eine genetische' (uma definição genética): 'Sie ist nämlich die sich ewig wiederholende Arbeit des Geistes, den articulierten Laut zum Ausdruck des Gedanken fähig zu machen'('Ela é, pois, o trabalho do espírito, que se repete constantemente para tornar possível que o som articulado expresse o pensamento'). Há um fator constante e uniforme subjacente a este 'Arbeit des Geistes' (trabalho do espírito): é isto que Humboldt chama a 'forma' da linguagem. Na linguagem somente são fixas as leis subjacentes de geração. A extensão e a maneira em 
fos como Charles Taylor - seguindo a trilha aberta por Heidegger - retomam a compreensão da linguagem como atividade apenas no que se refere a sua função de abertura do mundo: "Taylor tende a uma totalização dessa função da linguagem de abertura do mundo. Com isso, ele cai em um perspectivismo epistemológico, que o próprio Humboldt evita”. ${ }^{14}$

Podemos notar, nessa compreensão da linguagem como atividade, que o aspecto criador da linguagem comparece tanto no ponto de vista semântico quanto no ponto de vista pragmático adotados por Humboldt. E é justamente esse fato que faz de suas reflexões um marco importante não apenas para a lingüística, mas também para a filosofia contemporânea:

Humboldt leva a cabo uma mudança de paradigma que afeta não apenas a lingüistica, cujo desenvolvimento no século XX revela as conseqüências dessa mudança de maneira bastante clara, mas também a filosofia, para a qual a linguagem (vista como sistema de signos objetificados) nunca teve uma dimensão filosófica. Além disso, a mudança de paradigma levada a cabo por Humboldt ocorre em

que o processo gerativo opera na produção real da fala (ou na percepção da fala, que Humboldt considera como um desempenho parcialmente análogo) são totalmente indeterminadas"(Chomsky, N. Lingüistica cartesiana: um capitulo da história do pensamento racionalista. Petrópolis; São Paulo: Vozes; Editora da Universidade de São Paulo, 1972, p. 30).

14. Idem, p. 336. Não por acaso, Taylor enfatiza, em sua leitura dessa tradição, exclusivamente a dimensão semântica da linguagem: "Herder desenvolve uma noção bem distinta de expressão [em relação à tradição HobbesLocke-Condillac]. Isso está na lógica de uma teoria constitutiva, tal como acabo de descrevê-la. Essa noção nos diz que a linguagem constitui a dimensão semântica, ou seja, a posse da linguagem nos capacita a nos relacionar com as coisas de novas maneiras, digamos como loci de características, bem como ter novas emoções, metas ou relacionamentos e, mais do que isso, ser responsivos a questões que envolvam valores fortes. Poderíamos dizer: a linguagem transforma nosso mundo, usando esta última palavra num sentido claramente derivado de Heidegger. Falamos não sobre o cosmos lá fora, que nos precedeu e nos é indiferente, mas sobre o mundo dos nossos envolvimentos, incluindo todas as coisas que incorporam em seu significado para nós" (Taylor, C. "Heidegger, linguagem e ecologia". In: Argumentos filosóficos. São Paulo: Edições Loyola, 2000, p. 122). 
duas dimensões diferentes. Em sua dimensão cognitivo-semântica, essa mudança consiste em encarar a linguagem não como um mero sistema de signos, não como algo objetificável (intramundanamente), mas como algo constitutivo da atividade de pensar, como a própria condição de possibilidade dessa atividade. A linguagem é, então, elevada a um estatuto quase-transcendental, que reivindica contra a subjetividade a autoria das operações constitutivas da visão de mundo do sujeito (...) Em sua dimensão comunicativo-pragmática, a mudança consiste em ver esse caráter constitutivo da linguagem como o resultado de um processo ou atividade: especificamente, $a$ atividade de falar. Nesse sentido, a linguagem se torna a garantia da intersubjetividade da comunicaşão, a condição de possibilidade do entendimento entre falantes. ${ }^{15}$

No que se refere à primeira dimensão, a compreensão da linguagem como atividade revela-se no fato de que por meio dela "criam-se" novos "conceitos", novos "conteúdos" por meio dos quais o mundo se faz acessível. Humboldt, opondo-se a Kant, refere-se a essa atividade como uma síntese: "desde o primeiro elemento, a geração da linguagem é um processo sintético - e isso no sentido estrito da palavra - que cria algo que não existia em nenhuma de suas partes". ${ }^{16}$ No que se refere à segunda dimensão, a compreensão da linguagem como atividade revela-se na ideia da unificação através do diálogo. Segundo Habermas, "no processo de comunicação lingüística está em ação uma força capaz de estabelecer a unidade na multiplicidade de uma outra maneira, diferente da via da subsunção da variedade sob uma regra geral" ${ }^{17}$ No lugar do "eu penso" kantiano - associado à unidade transcendental da apercepção -, Humboldt coloca a intersubjetividade, representada pelas diferentes perspectivas dos participantes da comunica-

15. Lafont, C. The linguistic turn in hermeneutic philosophy, p. 17-8.

16. Humboldt, W. von. Schriften zur Sprachphilosophie (Werke III), p. 473.

17. Habermas, J. "Individuierung durch Vergesellschaftung: $\mathrm{Zu}$ Georg Herbert Mead Theorie der Subjektivität”. In: __ Nachmetaphysisches Denken. Frankfurt am Main: Suhrkamp, 1988, p. 201 (trad.: Habermas, J. "Individuação pela socialização: sobre a teoria da subjetividade de Georg Herbert Mead”. In:___. Pensamento pós-metafísico. Rio de Janeiro: Tempo Brasileiro, 1990, p. 196). 
ção, que buscam alcançar um entendimento entre si sobre algo no mundo. Nas palavras do próprio Humboldt:

a individualidade se destroça, mas de uma maneira tão maravilhosa que ela desperta, precisamente através da separação, o sentimento da unidade, aparecendo inclusive como um meio para produzi-la ao menos na ideia (...) Aqui, a linguagem vem a seu socorro de modo realmente maravilhoso, pois une no próprio momento em que individualiza e inclui na cápsula da expressão mais individual a possibilidade do entendimento universal. ${ }^{18}$

É certo que Humboldt em algumas passagens parece conceder uma primazia à primeira dimensão. Podemos lembrar, a título de exemplo, pelo menos dois momentos em que ele ressalta o nexo entre a "forma interna" da língua e uma determinada imagem de mundo que ela impõe aos povos e nações: na famosa introdução à obra sobre o Kawi, ele escreve: "a língua é, por assim dizer, a manifestação externa do espírito dos povos; sua língua é seu espírito e seu espírito é sua língua" ${ }^{19}$; no opúsculo sobre as diferenças na estrutura da linguagem humana, ele escreve: "cada língua traça ao redor da nação a que pertence um círculo do qual só é possível sair na medida em que ao mesmo tempo se passa para outro círculo de uma outra língua". ${ }^{20}$ Mas é certo também que em outros momentos ele assinala o primado da dimensão comunicativo-pragmática da linguagem, como podemos atestar na seguinte passagem:

o diálogo que verdadeiramente engrena uns aos outros, que troca ideias e sensações é, por assim dizer, o centro da linguagem, cuja essência não pode ser pensada senão como grito e eco, fala e resposta, que em suas origens, assim como em suas modificações não pertence a um único, mas a todos, que se situa nas profundezas solitárias do espírito de cada um, mas que apenas se evidencia na vida social". ${ }^{21}$

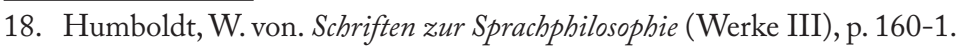

19. Idem, p. $414-5$.

20. Idem, p. $224-5$.

21. Idem, p. 81. 
Não se pode, pois, sobrepor uma dimensão à outra. Ao contrário, é preciso examinar como ambas se combinam no mesmo quadro. Assim, é preciso compreender a divisão de trabalho entre a "semântica das imagens lingüísticas do mundo" e a "pragmática formal da conversação". É preciso compreender que, paralelamente a um certo "particularismo semântico", coloca-se um universalismo da conversação. Isso porque "os participantes querem se compreender mutuamente e ao mesmo tempo se entender a respeito de alguma coisa, ou seja, alcançar se possível um acordo. E isso também se aplica ao entendimento buscado para além dos limites de diferentes comunidades lingüísticas". ${ }^{22}$ A conclusão que Habermas extrai disso é a seguinte: não há como não reconhecer que Humboldt foi responsável por desenhar os contornos de uma "arquitetônica da linguagem que até hoje permaneceu decisiva para uma transformação pragmática da filosofia kantiana”. ${ }^{23}$

Com essa incursão pela leitura que Habermas faz de Humboldt, talvez possamos compreender um pouco melhor aquelas transformações que Habermas promove na filosofia kantiana. A reformulação da pergunta kantiana a respeito das condições de possibilidade do conhecimento em uma pergunta pelas "condições normativas do entendimento possível" deve-se à substituição do paradigma do sujeito pelo paradigma da linguagem, entendendo esta não apenas em sua dimensão cognitivo-semântica, mas também e, sobretudo, em sua dimensão comunicativo-pragmática. A reformulação do "fato da razão" em um "fato da linguagem" devese a uma recepção da versão hermenêutica da teoria da linguagem - mais especificamente, a uma leitura de Humboldt -, pois explicita que o entendimento diz respeito às três funções principais da linguagem (a função cognitiva, que permite formar pensamentos e representar fatos; a função expressiva, que permite exprimir sen-

22. Habermas, J. "Hermeneutische und analytische Philosophie. Zwei komplämentare Speilarten der linguistischen Wende". In: ___. Wahrbeit und Rechtfertigung, p. 72 (trad.: Habermas, J. "Filosofia hermenêutica e filosofia analítica: duas versões complementares da virada lingüística”. In: Verdade e Justificação, p. 73).

23. Idem, p. 76 . 
timentos e suscitar sensações; e a função comunicativa, que permite comunicar algo, replicar e produzir acordos) e, nessa medida, diz respeito simultaneamente às condições de verdade, de justeza normativa e de veracidade subjetiva, correspondentes às três principais pretensões de validade associadas aos enunciados que proferimos cotidianamente.

Nesse ponto já se pode começar a notar uma outra conseqüência dessa transformação pragmática da filosofia kantiana. Refirimo-nos à maneira de conceituar as questões da diferenciação e da unidade da razão. É certo que elas ocupam boa parte das linhas de Habermas sobre o discurso filosófico da modernidade. Mas é certo também que elas se fazem presentes em suas reflexões sobre a linguagem. Basta, para atestá-lo, a leitura da seguinte declaração:

Eu pretendo elaborar o conteúdo normativo da ideia de entendimento implícito na linguagem e nas comunicações. Isso leva a um conceito complexo, que implica não apenas que entendemos o significado de atos de fala, mas também que o entendimento entre participantes da comunicação é produzido no que diz respeito a fatos, normas e também experiências (...) Com isso, mencionamos as três dimensões que o conceito de racionalidade comunicativa contém: a relação do sujeito de conhecimento com um mundo de acontecimentos e fatos; a relação do sujeito prático, na interação com outros sujeitos envolvidos e atuantes, com um mundo de sociabilidade; e, finalmente, a relação do sujeito sofredor e apaixonado, no sentido de Feuerbach, com sua própria natureza interna, com a sua subjetividade e com a subjetividade de outros. Essas são as três dimensões que saltam à vista quando se analisa os processos de comunicações da perspectiva dos participantes. ${ }^{24}$

A partir dessas palavras, gostaríamos de chamar a atenção para uma ou duas coisas. Como Kant, Habermas toma para si a tarefa de conceituar as diferenciações dos complexos de racionalidade, característica da modernidade cultural. No entanto, diferentemente daquele ele não o faz com base em uma teoria das

24. Habermas, J. "Dialektik der Rationalisierung". In: Unübersichtlichkeit. Kleine Politische Schriften V, p. 185. 
faculdades subjetivas do conhecimento, mas com os meios da teoria da linguagem. Nessa medida, ele interpreta a diferenciação dos âmbitos teórico, prático e estético não como a diferenciação dos domínios sobre os quais legislam o entendimento (Verstand), a razão (Vernunft) e a faculdade de julgar (Urteilskraft), mas como a diferenciação de pretensões de validade (pretensão de verdade, pretensão de justeza normativa e pretensão de veracidade) que os falantes associam a seus enunciados. Além disso, tal diferenciação não é compreendida a partir das possíveis relações de representação que se estabelecem entre sujeito e objeto, mas a partir das relações entre sujeitos, que, por meio de seus enunciados, referemse a um mundo de fatos (sobre o qual eles podem fazer afirmações verdadeiras ou falsas), a um mundo de normas compartilhadas (em relação ao qual eles podem proferir enunciados adequados ou justos) e a um mundo de experiências subjetivas (em relação ao qual eles podem se expressar sinceramente ou não, de maneira autêntica ou não).

Por outro lado, Habermas não descuida da questão da unidade da razão. Nas "Réplicas a objeções", de 1980, ele escreve:

as pretensões de validade da verdade proposicional, da justeza normativa e da veracidade subjetiva ou autenticidade, vinculadas na prática comunicativa cotidiana, são aspectos co-originários, que apenas na modernidade foram isolados uns dos outros, a ponto de as tradições culturais só poderem ser elaboradas sob cada um desses aspectos e os problemas tradicionais só poderem ser classificados como questões de verdade, de justiça e de gosto. A diferenciação da razão nesses complexos de racionalidade, aos quais as três críticas da razão de Kant se referem, só poderia ser anulada ao preço do próprio racionalismo ocidental. Nada mais distante de mim do que evocar a unidade substancial da razão, do que me tornar o advogado de uma tal regressão. ${ }^{25}$

Dado o fato da diferenciação da razão, Habermas procura pensar sua unidade recorrendo não ao modelo metafísico da uni-

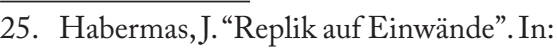
zur Theorie des kommunikativen Handelns, p. 499. 
dade substancial, mas à forma moderna de uma unidade procedimental. Expliquemos.

Em sua discussão sobre a "racionalidade procedimental", como um dos motivos do pensamento pós-metafísico, Habermas recorda que na tradição metafísica a razão é concebida como uma faculdade dependente dos conteúdos materiais do mundo, como uma faculdade que organiza tais conteúdos e que pode ser reconhecida neles. Assim, "a razão é razão do todo e de suas partes". ${ }^{26}$ $\mathrm{Na}$ modernidade, porém, em que se quebra essa unidade substancial, a razão se divide em racionalidades adequadas ao tratamento das questões específicas a cada um de seus âmbitos. Nas ciências experimentais, problemas empíricos passam a ser tratados no interior das comunidades de pesquisadores. $\mathrm{Na}$ moral e no direito, problemas práticos passam a ser tratados no contexto da comunidade de cidadãos de um Estado democrático e no contexto do sistema de direitos, independentemente, portanto, de qualquer tábua de mandamentos instituídos pela religião ou pelos valores tradicionais de uma dada comunidade. $\mathrm{Na}$ estética, a produção e a avaliação das obras de arte passam a não mais dependerem de regras rígidas e fixas instauradas desde a antigüidade, mas sim de procedimentos que dizem respeito unicamente à experiência estética do artista e do público. Assim, "a racionalidade (Rationalität) reduz-se a seu aspecto formal, na medida em que dissolve a racionalidade (Vernunftigkeit) dos conteúdos na validade dos resultados (...) a racionalidade procedimental não pode mais garantir uma unidade antecipada na pluralidade dos fenômenos". ${ }^{27}$ Diante desse quadro, não apenas a questão da diferenciação da razão, mas também a questão de sua unidade deve ser pensada em termos procedimentais. É esse um dos aspectos que Habermas ressalta em sua caracterização da filosofia kantiana, como podemos ler na seguinte passagem:

26. Habermas, J. "Motive nachmetaphysischen Denkens". In: Nachmetaphysisches Denken. Frankfurt am Main: Suhrkamp, 1988, p. 42 (trad.: Habermas, J. “Motivos do pensamento pós-metafísico". In: Pensamento pós-metafísico. Rio de Janeiro: Tempo Brasileiro, 1990, p. 44).

27. Idem, p. 42-3 (trad.: Idem, p. 44). 
Kant coloca no lugar do conceito substancial de razão da metafísica o conceito de uma razão que se dividiu em seus elementos e cuja unidade de agora em diante só tem caráter formal. Com efeito, ele separa do conhecimento teórico a faculdade da razão e a faculdade de julgar e assenta cada uma delas em fundamentos próprios. ${ }^{28}$

E é justamente esse aspecto que ele retoma em sua intervenção no debate contemporâneo a respeito da crítica da racionalidade: "pode ser fora de moda, mas acredito que, como Kant, também nos colocamos hoje diante do problema de esclarecer onde o conhecimento objetivo, o discernimento moral e a faculdade de julgar estética encontram sua unidade procedimental". ${ }^{29}$ No entanto, não obstante a retomada da questão kantiana, Habermas procura abordá-la com o aparato de sua teoria da linguagem. A possibilidade para tal transformação é dada, mais uma vez, pela recepção da virada lingüística. Disso resulta que Habermas coloque a questão não como a unidade procedimental das faculdades do conhecimento, mas como a "unidade procedimental das fundamentações discursivas".

O que subjaz a essa transformação e às outras mencionadas acima é uma reformulação profunda na noção mesma de racionalidade. Para Habermas, a racionalidade designa não um conjunto de faculdades de subjetivas, mas "uma disposição dos sujeitos capazes de falar e agir para adquirir e aplicar um saber falível". ${ }^{30}$ Se no quadro da filosofia da consciência - no qual a filosofia kantiana se insere -, "a racionalidade é medida pela maneira como o sujeito solitário se orienta pelos conteúdos de suas representações e de seus enunciados"; na teoria habermasiana - herdeira da virada lingüística -, "a racionalidade encontra sua medida na capa-

28. Habermas, J. Moralberwußtsein und kommunikatives Handeln. Frankfurt am Main, Suhrkamp, 1983, p. 10 (trad.: Habermas, J. Consciência moral e agir comunicativo. Rio de Janeiro: Tempo Brasileiro, 1989, p. 18). Sobre as questões da diferenciação e da unidade da razão em Kant, cf. Terra, R. Passagens. Estudos sobre a filosofia da Kant. Rio de Janeiro: Editora UFRJ, 2003.

29. Habermas, J. "Untiefen der Rationalitätskritik". In: Die Neue Unübersichtlichkeit. Kleine Politische Schriften V, p. 136.

30. Habermas,J. Derphilosophische Diskurs der Moderne,p. 366 (trad: Habermas, J. O discurso filosófico da modernidade, p. 437). 
cidade (Fäbigkeit) de os participantes responsáveis da interação orientarem-se pelas pretensões de validade que estão assentadas no reconhecimento intersubjetivo". ${ }^{31}$ Desenham-se com isso os contornos de um conceito plural e procedimental de racionalidade. "Procedimental", pois seus critérios são dados pelos procedimentos discursivos de desempenho das pretensões de validade associadas aos enunciados. "Plural", pois engloba as pretensões de verdade proposicional, de justeza normativa, de veracidade subjetiva e adequação estética, correspondentes aos âmbitos teórico, prático e estético. Cumpre notar que a caracterização da racionalidade como plural impõe a tarefa de revelar a maneira como suas diferentes dimensões, expressas pelas diferentes pretensões de validade e pelas respectivas formas argumentativas, se relacionam entre si. Como chama atenção Martin Seel, Habermas tem diante de si a tarefa de elaborar

uma teoria das diferentes formas de racionalidade, cuja diferenciação é constitutiva para a existência de uma razão 'comunicativa'. Esse fio condutor de crítica da racionalidade coloca para as análises de Habermas uma dupla tarefa. Elas têm de destacar o sentido intrinseco das racionalidades teórico-instrumental, moral-prática e estético-expressiva e têm também de elucidar seu nexo na ação orientada para o entendimento. ${ }^{32}$

Seel tem dúvidas quanto à possibilidade de sucesso na realização dessa tarefa. Ele argumenta que a unidade da razão não deve ser identificada à "unidade procedimental das fundamentações discursivas", à unidade das formas de argumentação, como faz Habermas. Trata-se, antes, de um entrosamento das formas de argumentação e "esse entrosamento tem a forma de dependências completamente materiais (ligadas à pressuposição recíproca do conteúdo), sem que se possa evidentemente determinar e repre-

31. Idem, ibidem (trad.: Idem, ibidem).

32. Seel, M. "Die zwei Bedeutungen 'kommunikativer' Rationalität. Bemerkungen zu Habermas' Kritik der pluralen Vernunft”. In: Honneth, A.; Joas, H. (Hg.). Kommunikatives Handeln. Beiträge zu Jürgen Habermas' "Theorie des kommunikativen Handelns". Frankfurt am Main: Suhrkamp, 1986, p. 53. 
sentar esse material por meio de uma teoria filosófica unificada". ${ }^{33}$ Habermas aceita em parte as críticas de Seel. De um lado, promove a transformação do conceito kantiano de "faculdade de julgar" em uma "faculdade de julgar assentada na própria ação comunicativa", uma "faculdade de julgar associada à atitude performativa dos que agem comunicativamente" ${ }^{34}$ Além disso, ele diz que, embora a passagem (Übergang) de uma forma a outra seja regulada pela lógica da argumentação, ela depende muitas vezes "dos desfiladeiros no curso da argumentação" ou de "problemas que vêm a nosso encontro". Mas, por outro lado, ele continua a manter a ideia de que as pretensões de validade formam um sistema. Seja como for, Habermas parece fazer jus à ideia, expressa de maneira lapidar por Albrecht Wellmer, de que

os discursos estéticos, prático-morais e 'factuais' não estão separados uns dos outros por um abismo, mas estão relacionados de múltiplas maneiras - mesmo que a validade estética, moral ou veritativa representem diferentes categorias de validade, que não podem ser reduzidas a uma categoria de validade. Trata-se aqui (a única coisa de que se poderia tratar) não de uma 'reconciliação dos jogos de linguagem', mas de uma "permeabilidade" recíproca

33. Idem, p. 64. Para uma discussão mais detalhada das críticas de Seel a Habermas e da réplica deste, cf. Repa, L. A transformação da filosofia em Jürgen Habermas: os papéis de reconstrução, interpretação e crítica. São Paulo: Singular; Esfera Pública, 2008, p. 217-28.

34. Habermas, J. "Entgegnung". In: Honneth, A.; Joas, H. (Hgg.). Kommunikatives Handeln. Beiträge zu Jürgen Habermas' "Theorie des kommunikativen Handelns", 1986, p. 343. Habermas esclarece o conceito de "atitude performativa" nos seguintes termos: "a atitude performativa corresponde à orientação do falante para o entendimento e exclui a orientação para o sucesso. $\mathrm{Na}$ atitude performativa, o falante pode adotar uma postura objetivadora em relação ao mundo dos estados de coisas existentes, uma postura conforme à norma ou desviante à norma em relação ao mundo social, ou uma postura expressiva em relação a algo de seu próprio mundo subjetivo; a atitude performativa assegura a meta superior de alcançar o entendimento por regular a passagem de uma a outra e garantir a consistência de significado na inter-transferência das atitudes objetivadora, conforme à norma e expressiva" (Habermas, J. "Reply to Skjei". Inquiry, vol 28, no 1, 1985, p. 108-9). 
dos discursos: a superação da razão una em um jogo conjunto de racionalidades plurais. ${ }^{35}$

A fim de compreender em toda sua amplitude o conceito de racionalidade de Habermas, é preciso compreender não apenas a maneira como ele radicaliza a perspectiva kantiana ${ }^{36}$, mas é preciso compreender também a maneira como ele retoma e radicaliza a ideia da "transformação pragmática da filosofia kantiana" introduzida por Humboldt.

\section{Bibliografia}

ALMEIDA, G. A. de. "Kant e o facto da razão". In: MacDOWELL, J. A. (org.). Saber filosófico, história e transcendência. São Paulo: Ed. Loyola, 2002.

CHOMSKY, N. Lingüistica cartesiana: um capitulo da história do pensamento racionalista. Petrópolis; São Paulo: Vozes; Editora da Universidade de São Paulo, 1972.

HABERMAS, J. Moralbewußtsein und kommunikatives Handeln. Frankfurt am Main: Suhrkamp, 1983.

"Replik auf Einwände". In:

Vorstudien und Ergänzungen zur Theorie des kommunikativen Handelns. Frankfurt am Main: Suhrkamp, 1984.

. Der philosophische Diskurs der Moderne. Frankfurt am Main: Suhrkamp, 1985.

"Dialektik der Rationalisierung". In: Die Neue Unübersichtlichkeit. Kleine Politische Schriften V. Frankfurt am Main: Suhrkamp, 1985.

. "Reply to Skjei". Inquiry, vol 28, no 1, 1985.

"Untiefen der Rationalitätskritik". In:

Die Neue Unübersichtlichkeit. Kleine Politische Schriften V. Frankfurt am Main: Suhrkamp, 1985.

35. Wellmer, A. Zur Dialektik von Moderne und Postmoderne. Vernunftkritik nach Adorno. Frankfurt am Main: Suhrkamp, 1985, p. 108-9.

36. Sobre a radicalização da perspectiva kantiana levada a cabo por Habermas, que, como procuramos mostrar, representa apenas metade do problema, cf. Terra, R. Passagens. Estudos sobre a filosofia da Kant, p. 22. 
"Entgegnung". In: HONNETH, A.; JOAS, H. (Hgg.). Kommunikatives Handeln. Beiträge zu Jürgen Habermas' "Theorie des kommunikativen Handelns". Frankfurt am Main: Suhrkamp, 1986.

"Individuierung durch Vergesellschaftung: Zu Georg Herbert Mead Theorie der Subjektivität". In: Denken. Frankfurt am Main: Suhrkamp, 1988.

$$
\text { "Motive nachmetaphysischen Denkens". In: }
$$

Nachmetaphysisches Denken. Frankfurt am Main: Suhrkamp, 1988.

. Consciência moral e agir comunicativo. Rio de Janeiro: Tempo Brasileiro, 1989.

."Individuação pela socialização: sobre a teoria da subjetividade de Georg Herbert Mead”. In: . Pensamento pós-metafísico. Rio de Janeiro: Tempo Brasileiro, 1990.

."Motivos do pensamento pós-metafísico". In: Pensamento pós-metafísico. Rio de Janeiro: Tempo Brasileiro, 1990.

"Hermeneutische und analytische Philosophie. Zwei komplämentare Speilarten der linguistischen Wende". In: Wabrheit und Rechtfertigung. Frankfurt am Main: Suhrkamp, 1999.

O discurso filosófico da modernidade. São Paulo: Martins Fontes, 2000.

"Filosofia hermenêutica e filosofia analítica: duas versões complementares da virada lingüística”. In: Verdade e Justificação. São Paulo: Edições Loyola, 2004.

HAMANN, J. G. "Metacrítica sobre o purismo da razão". In: GIL, F. (org.). Recepscão da Crítica da razão pura: antologia de escritos sobre Kant (1786-1844). Lisboa: Fundação Calouste Gulbenkian, 1992.

HUMBOLDT, W. von. Schriften zur Sprachphilosophie (Werke III). Darmstadt: Wissenchaftliche Buchgesellchaft, 2002.

LAFONT, C. “Apertura del mundo' y referencia”. In: VIEJA, M. T. L. de la (ed.). Figuras del logos: entre la filosofía y la literatura. México D. F.: Fondo de Cultura Económica, 1994.

; PEÑA, L. "La tradición humboldtiana y el relativismo lingüístico”. In: DASCAL, M. (Ed.). Filosofia del languaje II. Pragmática. Madrid: Editorial Trotta, 1999.

. The linguistic turn in hermeneutic philosophy. Cambridge, Mass.: MIT Press, 1999.

McCARTHY, Thomas. Ideals and illusions: on reconstruction and deconstruction in contemporary Critical Theory. Cambridge, Mass.: MIT Press, 1993. 
REPA, L. A transformação da filosofia em Jürgen Habermas: os papéis de reconstrução, interpretação e crítica. São Paulo: Singular; Esfera Pública, 2008.

SEEL, M. "Die zwei Bedeutungen 'kommunikativer' Rationalität. Bemerkungen zu Habermas' Kritik der pluralen Vernunft”. In: HONNETH, A.; JOAS, H. (Hg.). Kommunikatives Handeln. Beiträge zu Jürgen Habermas' "Theorie des kommunikativen Handelns". Frankfurt am Main: Suhrkamp, 1986.

TAYLOR, C. "Heidegger, linguagem e ecologia”. In: Argumentos filosóficos. São Paulo: Edições Loyola, 2000.

TERRA, Ricardo. Passagens. Estudos sobre a filosofia da Kant. Rio de Janeiro: Editora UFRJ, 2003.

WELLMER, A. Zur Dialektik von Moderne und Postmoderne. Vernunftkritik nach Adorno. Frankfurt am Main: Suhrkamp, 1985. 